\section{Journals should set a new standard in transparency}

SIR - We applaud your commitment, as expressed in the Editorial "Peer review and fraud" (Nature 444, 971-972; 2006), to raising peer-reviewer awareness about detecting fraud. For studies involving humans, independent research ethics committees (in the United States, institutional review boards) provide

the first independent critical scrutiny of research protocols. We recently examined the instructions to authors of 103 medical journals and found that none requires authors to provide to readers (as online supplementary information accompanying the publication) the protocols approved by these committees.

As concern increases about the integrity of published scientific research, we believe that biomedical journals should establish a new standard in human-research transparency. They should require authors to state at submission - and, where judged necessary, in their published articles - that the research has been approved by the relevant ethical committees. All journals publishing research on non-human animals ("Animal experiments under fire for poor design" Nature 444, 981; 2006) should do the same for non-human animal protocols.

Journals should also require authors to provide the full protocols approved by these committees for the editors and peer reviewers, and to allow the journal, if it wishes, to publish these protocols as online supplementary information accompanying publication of the main paper.

Robert P. Dellavalle ${ }^{\star} \uparrow$, Kristy Lundahl $\uparrow$, Scott R. Freeman $\dagger^{\prime}$, Lisa M. Schilling $\dagger$ *Department of Veterans Affairs Medical Center, 1055 Clermont St, Denver, Colorado 80220, USA †University of Colorado at Denver and Health Sciences Center, Aurora, Colorado, USA

\section{Wise words from women aren't among top sellers}

SIR - Jon Turney's Books and Arts article "Top of the pops" (Nature 444, 819; 2006) begins by asking "What's special about the best popular science books?". From his choice of examples - 11 authors, 13 books - one answer is obvious: they were all written by men.

As a female scientist whose Brainwashing: The Science of Thought Control (Oxford Univ. Press, 2004) was one of four books shortlisted for the prestigious 2005 Times Higher Education Supplement 'Young Academic Author of the Year' award, and as one of two women authors (with Patricia Fara) on the Royal Society's 2005 Aventis Prize long-list of 13, I recognize that Turney was looking at best-selling popular rather than academic books, and that 2006 may have been a leaner year for women authors. And I note that Mary Purton's accompanying "2006 all wrapped up" (Nature 444, 821-822; 2006) includes the novelist Allegra Goodwin and translator Carol Brown Janeway.

Still, I am glad that some organizations, such as the Times Higher Education

Supplement and the Royal Society, include female science writers among their 'best'. Kathleen Taylor

Department of Physiology, Anatomy and Genetics, Oxford University,

Sherrington Building, Parks Road,

Oxford, OX13PT, UK

\section{Polluting effects of Brazil's sugar-ethanol industry}

SIR - As Brazilian environmental scientists, we believe that the Business Feature "Drink the best and drive the rest" 1 understates the serious environmental and social problems associated with Brazil's sugar-cane ethanol industry. For instance, although you say that soil erosion is a "potentially" damaging sideeffect of sugar-cane cultivation, there is abundant scientific evidence already that environmental degradation from soil erosion in sugar-cane fields is widespread ${ }^{2}$. In the state of São Paulo, which is the core of the ethanol industry in Brazil, estimated rates of soil erosion in sugar-cane fields are up to 30 tonnes of soil per hectare per year. Moreover, despite laws to protect the riparian buffers that prevent soil inputs to rivers and streams, only $30 \%$ of riparian zones have been preserved in river basins.

The burning of sugar-cane fields before manual harvesting twice a year is another serious environmental problem related to the ethanol industry in Brazil. Although a law passed in 2002 by the state of São Paulo decrees that, by $2006,30 \%$ of the sugar-cane fields with slopes lower than $12 \%$ (called mechanizable areas) should not be burned, farmers have been reluctant to replace cheap manual labour with more expensive mechanized harvesting. The deadlines imposed to reduce the burning of sugar-cane fields have been postponed several times, under pressure by sugar-cane farmers. Thus, it is likely that smoke pollution from sugarcane fields will continue to be a major problem in São Paulo and other Brazilian states for many years, leading to further acidification of the already poor tropical soils ${ }^{3}$. Additionally, high particulate concentrations in the atmosphere from sugarcane burning have been associated with a growing number of human respiratory diseases in sugar-cane regions ${ }^{4,5}$.

Last but not least, although the sugar-cane industry generates jobs in Brazil, working conditions, especially for manual harvesters, are extremely poor and often associated with causes of death. Thus - although we agree that Brazil's ethanol industry is "able to get better" - from an environmental and social standpoint, it is far from being as good as you portray.

We believe that the present ethanol industry and proposals for expansion of ethanol production in Brazil and worldwide should be carefully evaluated, to avoid environmental and social problems far outweighing long-term economic gains. Luiz Antonio Martinelli`, Solange Filoso $†$

${ }^{\star}$ Centro de Energia Nuclear na Agricultura, Avenida Centenário 303, 13416-000,

Piracicaba, SP, Brazil

†Department of Entomology, University of

Maryland, 4112 Plant Sciences Building,

College Park, Maryland, 20742-4415, USA

1. Nature $444,670-672(2006)$

2. Sparovek, G. \& Schnug, E. Soil Sci. Soc. Am. J. 65 1479-1486 (2001).

3. Krusche, A. V. et al. Environ. Pollut. 121, 389-399 (2003).

4. Arbex, M. A. et al. J. Air Waste Manag. Assoc. 50, 1745-1749 (2000)

5. Cançado, J. E. D. et al. Environ. Health Persp. 114, 725-729 (2006).

\section{Magenta and yellow in images is not a bright idea}

SIR - Chris Miall, in Correspondence ("Readers see red over low-impact graphics" Nature 455, 147; 2007), points out that a small but significant proportion of the population have difficulty distinguishing colours in red/ green images. For this reason, several journals now require images to be published in other colour pairs, the most common being magenta and yellow.

However, when using colours to evaluate protein co-localization, for example, as is now common in confocal microscopy data, some of the alternative colour schemes just do not work. Magenta and yellow in overlay produce 'almost white' - virtually indistinguishable from the yellow in tiny images.

Red and green, the standard colour pair, produce yellow when overlaid, and this is very easy to interpret. I suggest that journals continue to publish these images in red/green, but that they make alternatively coloured images available online as supplementary information for readers who have impaired colour vision.

John Runions

School of Life Sciences,

Oxford Brookes University,

Gipsy Lane, Oxford OX3 OBP, UK

Contributions to Correspondence may be submitted to corres@nature.com. They should be no longer than $\mathbf{5 0 0}$ words, and ideally shorter. Published contributions are edited. 